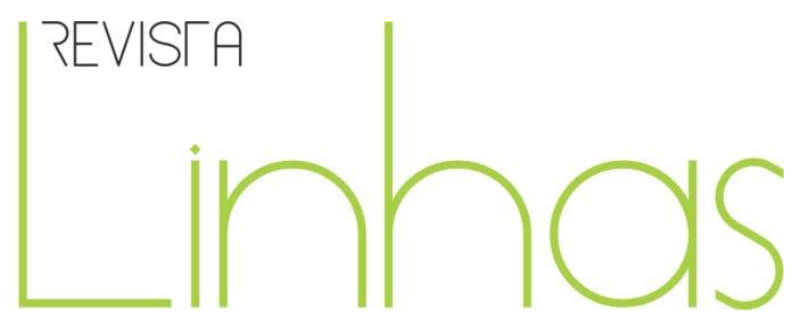

\title{
Pensar um sucesso alternativo na universidade - Reclassificar experiências de professores e de estudantes com base na auto-socioanálise
}

\begin{abstract}
Resumo
Este artigo oferece uma análise reflexiva sobre uma experiência coletiva de ensino realizada no âmbito de um sistema de apoio ao sucesso da universidade (um curso destinado a ser dedicado à "expressão escrita e oral"), dentro do departamento de sociologia da universidade de Nantes entre 2016 e 2019. O curso está centralizado na realização, pelos alunos, de uma autoanálise socioeconômica. O artigo analisa essa experiência como um "sucesso » educacional relativo, indo além do significado institucional do termo para defini-lo de maneira subjetiva e decompor suas manifestações. Se, em relação aos indicadores institucionais, este exercício e seu impacto são mínimos, destacamos como professores e alunos o adotam e investem. As fontes desse sucesso revelam processos de requalificação das experiências de ensino e aluno e sua relação com a universidade.
\end{abstract}

Palavras-chave: Práticas de ensino. Condições de trabalho. Sucesso acadêmico. Relacionamento com a universidade.
Frédérique Letourneux

L'École des hautes études en sciences sociales - EHESS - França

frederique.letourneux@univnantes.fr

Juliette Mengneau

Université de Nantes - França juliette.mengneau@etu.univnantes.fr

\section{Anna Mesclon}

Université de Nantes - França anna.mesclon@univ-nantes.fr

\section{Daniel Veron}

L'École des hautes études en sciences sociales - EHESS - França dveron@parisnanterre.fr

\footnotetext{
Para citar este artigo:

LETOURNEUX, Frédérique; MENGNEAU, Juliette; MESCLON, Anna; VERON, Daniel. Pensar um sucesso alternativo na universidade - Reclassificar experiências de professores e de estudantes com base na autosocioanálise. Revista Linhas. Florianópolis, v. 21, n. 45, p. 233-259, jan./abr. 2020. Título original: Penser une réussite alternative à l'université. Requalifier les expériences enseignantes et étudiantes à partir l'autosocioanalyse. Tradução: Fernando Coelho.
} 


\title{
Considering an alternative measure of success at university - When auto-sociolanalysis requalifies teachers' and students' experiences
}

\begin{abstract}
This article offers a reflexive analysis around a collective teaching experience that took place in the Sociology department of Nantes University (France), between 2016 and 2019. The course had the students carry out an "auto-socioanalysis". This paper analyzes this experience as a relative "success", not necessarily in the institutional sense, but by taking a subjective perspective and by questioning the different dimensions of "success". Although according to institutional indicators, what the exercise accomplishes appears to be marginal, we underline the way in which teachers/lecturers and students seize it and invest time and energy in it. The mechanisms of this particular success illustrate the way students' and teachers' experiences and their relationship to university are being transformed.
\end{abstract}

Keywords: Pedagogical practices. Teaching conditions. Academic success. Relations to university. 


\section{Introdução}

No cerne das controvérsias sobre " a crise da universidade » (BODIN e ORANGE, 2013), a questão do " sucesso » poderia aparecer como um objetivo político consensual. Entretanto, entre as taxas de inserção profissional, aquisição de um corpus de saberes, ou a construção de um espírito crítico, os critérios para avaliar o sucesso estão longe de encontrar um consenso, chegando a ponto desse conceito valer para realidades muitas vezes contraditórias. Enquanto, para justificar novas reformas, sejam regularmente apresentadas as taxas supostamente catastróficas de «fracasso » de certas áreas (BODIN e MILLET, 2011) ou a inadequação - também suposta - de certos públicos à instituição universitária, mais raras são as narrativas de experiências de formas modestas e relativas de «sucesso»"

Má orientação, nível insuficiente, ausência de ascese estudantil, diletantismo, indisciplina: são numerosos os males feitos a determinados públicos que investem nos bancos da universidade no primeiro ano de licenciatura e, mais particularmente, nos bacharéis em tecnologia ou profissional. Em resposta, a Lei de « Orientação e Sucesso dos Estudantes » de 2018 chegou ao fim abrupto do debate, introduzindo a seleção às portas do ensino superior ${ }^{2}$. Esta solução desigual é, no entanto, acompanhada de dispositivos de apoio educacional, previstos no contexto da admissão condicional (Parcoursup «sim, se »). Na realidade, esta vocação de «acompanhamento ao sucesso » dos públicos que parecem dominar mal os códigos escritos e orais impostos pela universidade, foi há muito tempo instaurada em vários dispositivos estabelecidos pelas equipes pedagógicas, e na

\footnotetext{
${ }^{1}$ Os autores agradecem Corinne Davault e Marie-Paule Couto por suas numerosas e preciosas observações sobre este texto.

${ }^{2}$ Esta reforma na verdade construiu a possibilidade de selecionar previamente os fluxos de estudantes, é a vocação da plataforma de orientação para os bacharéis, chamada « Parcoursup ». Nessa plataforma, o bacharel faz seus votos de prosseguimento no ensino superior e para cada um deles, ele recebe uma resposta. Se ele pode ser recusado ou aceito, ele pode também, e esta é uma das novidades da lei, receber como resposta um «sim, se » por parte das universidades, ou seja, uma admissão condicionada ao seguimento de módulos de nivelamento. A reforma consagra desse ponto de vista uma mudança radical de paradigma ao romper com o processo de democratização do acesso ao saber. Se seu impacto em grande parte ainda não foi medido, parece claro que em primeiro lugar é a juventude dos meios populares, e principalmente a parte feminina, que verá o acesso ao ensino superior se restringir (COUTO et BUGEJABLOCH 2018).
} 
maioria das vezes por professores não-titulares, marcados por condições precárias de emprego (BOURGIN, 2011 ; DAVID, 2017)33. Desde então parece importante se interrogar sobre a maneira pela qual o "sucesso", sistematicamente citado nas normas institucionais em um contexto de massificação dos primeiros ciclos universitários e de precarização do pessoal de ensino superior, é apreendido concretamente nas práticas educativas.

Este artigo oferece uma análise reflexiva de uma experiência coletiva de ensino conduzida no âmbito de um desses dispositivos de apoio ao sucesso universitário (um curso voltado à « expressão escrita e oral »), dentro do departamento de sociologia da Universidade de Nantes entre 2016 e 2019. O objetivo aqui é de rever como um contexto muito específico levou quatro jovens professores-pesquisadores não-titulares a usar uma ferramenta educacional para acompanhar os alunos e construir um consenso em torno de um exercício bem específico: a auto-socioanálise $e^{4}$.

Por auto-socioanálise, entendemos uma abordagem que consiste em tomar-se a si próprio como um objeto e distinguir uma trajetória, conferindo-lhe uma dimensão coletiva. Partindo do postulado de que a reflexividade é libertadora e que um melhor conhecimento de si e de seu lugar no mundo social é uma força (HILGERS, 2006), a ideia deste curso foi de colocar no centro da reflexão os mecanismos sociais que influenciam as trajetórias de nossos alunos, que podem dar sentido à sua jornada e, assim, « desfatalizar » a realidade (CHARPENTIER e ERNAUX, 2005), mesmo que essa revelação às vezes seja dolorosa (KAKPO e LEMÊTRE, 2019). Além disso, considerando os « saberes da experiência » (DEAUVIEAU, 2007) dos estudantes como material legítimo e digno de

\footnotetext{
${ }^{3}$ As pessoas que ensinam na universidade, o fazem mediante diversos estatutos, dos quais o mais perene é o estatuto do professor-pesquisador titular, que existe em paralelo aos contratos de um ou dois anos (os Adidos Temporários de Ensino e Pesquisa) reservados aos doutorandos ou aos jovens doutores, mas também de contratos ocasionais (vacataires). Estes últimos constituem o estatuto mais precário no sentido em que são utilizados pelas universidades para suprir necessidades pedagógicas não cobertas pelos empregos estáveis, evitando os encargos a eles associados, e são atribuídas em número significativo a professores que não integram verdadeiramente a equipe pedagógica, e assumem cursos que não foram atribuídos ao pessoal mais estabilizado. Se os ATER devem, assim como os titulares, assegurar 192 horas de ensino (as aulas magistrais tendo peso de 1,5), os professores ocasionais são remunerados pela hora de ensino e não têm qualquer visibilidade quanto ao número de horas e sua possível recondução de um ano para o outro.

4 Para sustentar o relato desta experiência, este artigo se apoia sobre materiais variados: pastas dos alunos, nossos materiais do curso (corpus de textos, tramas das sessões, documentos distribuídos aos estudantes, etc.), mas igualmente e-mails (entre colegas ou com os alunos), atas de reunião, ou ainda balanços de aulas redigidos como notas de observação.
} 
interesse, procuramos operar uma forma de requalificação universitária de sua experiência social, propondo-Ihes de desconstruíla sociologicamente. Convencidos de que a prática e a teoria se beneficiam do emaranhado (ANNOOT, 2012), tentamos adotar um «regime de apresentação do saber » (JOUNIN, 2014) que insista na necessidade de encarnar, tanto quanto possível, os conceitos na experiência sensível dos estudantes, para lhes tornar atores de seus aprendizados.

Este artigo propõe conceber o « sucesso » de um projeto pedagógico não em si, mas para si mesmo, partindo de sua dimensão subjetiva para decompor suas manifestações. As molas deste sucesso se baseiam em processos de requalificação da experiência do aluno e do trabalho de ensino. Essas formas situadas de sucesso devem finalmente ser compreendidas em sua singularidade : por um lado, baseiam-se em « um dom contra um dom pedagógico ", com base em um investimento excessivo no ensino e em entusiasmo estudantil; por outro lado, produzem efeitos - talvez marginais, mas concretos - nas experiências dos alunos, mas também em nosso próprio relacionamento com a profissão de professor-pesquisador.

Em primeiro lugar, mostramos como nosso superinvestimento neste curso deve ser entendido em termos do contexto político, institucional e local, mas também em termos de nosso posicionamento social, nossos estatutos, nossas trajetórias e nossa relação com o trabalho. Esse superinvestimento baseia-se em grande parte no trabalho invisível - às vezes gratuito (SIMONET, 2018) - de funcionários precários que demonstram, em uma universidade em crise, uma « boa vontade pedagógica » (SOULIÉ, 2002) ancorada em uma relação vocacional com o trabalho. Em segundo lugar, apresentamos a etapa pedagógica que constitui o dispositivo implementado, enfatizando os limites inerentes ao seu registro em um ambiente universitário. Por fim, analisamos os efeitos da dupla requalificação que opera esse dispositivo, observando as formas diferenciadas de apropriação do exercício pelos alunos, bem como a maneira como ele assume significado na definição de nossa profissão. 


\section{Dar sentido a seu trabalho em um contexto institucional « em crise »}

O superinvestimento que nos levou a construir, com cada peça e de maneira coletiva, um dispositivo pedagógico de auto-socioanálise se explica tanto pela ambivalência, própria da condição precária, entre relação de exploração e o arranjo das margens de autonomia (CINGOLANI, 2014), mas também em termos de nossas trajetórias sociais singulares e de um contexto propício a uma intensa sociabilidade.

\subsection{Um curso desvalorizado para os jovens professores-pesquisadores ocasionais}

A apropriação singular de um curso de metodologia que operamos se explica em primeiro lugar quanto à situação do ensino superior. Em 2016-2017, os professores não permanentes representavam $21,7 \%$ de todo o corpo docente no ensino superior ${ }^{5}$, sem contar os professores ocasionais que constituem um grupo importante para o ensino nos primeiros ciclos ${ }^{6}$. - O recrutamento de professores não permanentes é ainda mais importante nas áreas de letras e ciências humanas, que são regularmente forçadas a recrutar uma força de trabalho temporária capaz de absorver, graças à sua «flexibilidade », a escassez de professores titulares e os transtornos demográficos que caracterizam os «fluxos » anuais de estudantes (LE SAOUT ET LOIRAND, 1998 ; SOULIE, 1996). Além disso, a divisão do trabalho universitário com frequência entrega para os professores não titulares - entre os quais os doutorandos, os jovens doutores, os empregados ocasionais - os ensinos menos valorizados, que estão por baixo na hierarquia simbólica estruturada por diferentes escalas de valores que se cruzam (as aulas magistrais em preferência aos trabalhos dirigidos, teóricos em preferência aos metodológicos, mestrados em preferência às licenciaturas, o terceiro ano de licenciatura (L3), ou o segundo (L2) em preferência ao primeiro (L1).

A situação em Nantes não é exceção ao que se constata em geral sobre a organização do trabalho, a distribuição de recursos e a composição do público estudantil. Na UFR (unidade de formação e pesquisa) em sociologia, em 2016, havia 26 professores

\footnotetext{
${ }^{5}$ Nota da DGRH do Ministério do Ensino Superior e da Pesquisa, n 4 , maio de 2018, p. 2.

${ }^{6}$ É nessa parte do ensino superior que os ocasionais foram os mais numerosos (31 \%) em 2017 (ibid., p. 5).
} 
titulares, nove contratados e quarenta e um ocasionais. Os professores com estatutos precários realizam a maior parte de seus serviços no L1 e ministram os cursos menos valorizados nos modelos de ensino. Em 2013, 90\% do serviço dos doutorandos contratados estava em L1 e 10\% em L3. Para os Adidos Temporários de Ensino e Pesquisa (ATER), seu serviço é de $80 \%$ em L1, 12\% em L2 e 8\% em L3. A contrário, os professores pesquisadores-titulares (MCF) realizam apenas $28 \%$ de seu serviço no primeiro ano (17\% para os professores), o resto se espalhando por todos os outros níveis (DAVID, 2017)7.

Nos últimos vinte anos, em um contexto de massificação dos primeiros ciclos universitários, foram criados cursos de metodologia do trabalho universitário, em particular no âmbito do Plano de Sucesso na Licenciatura, para fortalecer a adequação educacional dos primeiros ciclos. Bem desvalorizados pelos titulares, esses cursos simbolizam as contradições entre as medidas pedagógicas para o sucesso do maior número de estudantes e a penúria de recursos alocados ao ensino universitário (BODIN ET ORANGE, 2013 ; SINIGAGLIA, 2018).

Em Nantes, a implementação desses dispositivos levou à criação de um curso de «Expressão escrita e oral » no segundo semestre de L1. Explícito quanto à sua vocação, este curso se preocupa desde o início com o «remise à niveau » através de acompanhamento pedagógico reforçado. Professores precários (dois de nós são ATER, outro é temporário e o último começa este ano um contrato de doutorado com carga de ensino), relegados com mais frequência a ministrar TD L1, nos encontramos então em primeira linha para garantir este curso de metodologia ${ }^{8}$.

Assim, como este curso tem pouco tempo de existência institucional e a sua pedagogia nem é tão contemplada pelas equipes de ensino, nem reconhecida por inteiro

\footnotetext{
7 Em relação ao público, 63\% dos alunos do primeiro ano matriculados em 2015-2016 em sociologia representam $63 \%$ de um exame (baccalauréat) geral, $24 \%$ possuem um baccalauréat tecnológico e apenas $8 \%$ um baccalauréat profissional. Os filhos de operários e empregados estão representados majoritariamente $(41,1 \%)$ entre os estudantes, na frente dos filhos de executivos e de profissões intelectuais superiores (20\%) ou de profissões intermediárias (15,9\%). Mais de 58\% dentre eles são bolsistas. Finalmente, no conjunto da promoção daquele ano, a matrícula em sociologia foi a primeira opção apenas para $48 \%$ deles (Fonte: pesquisa anual entre os ingressantes).

${ }^{8}$ Sem surpresa, e com exceção dos três anos em que o número de grupos de TD é particularmente baixo, a maioria dos professores não permanentes (ATER, instrutor, monitor, temporário) o ensina. Entre 2004 e 2015, foi fornecido em média por duas vezes mais professores não permanentes do que professores. Em onze anos, e dos dezoito palestrantes que o ensinaram, apenas um deles interveio sistematicamente, exceto por um ano. É também o primeiro curso a sofrer cortes no orçamento. Desconectado das palestras, seu lugar no modelo é marginal e seu volume horário aumentou de 18 para 12h / TD em dez anos.
} 
nas trajetórias de jovens pesquisadores à espera de uma posição hipotética, o grupo de trabalho que criamos nos conduz a um intenso comprometimento com este curso.

\subsection{Dar sentido ao seu trabalho}

Em primeiro lugar, o comprometimento nessa dinâmica de trabalho coletivo se traduz por uma dedicação de tempo considerável, tanto para a preparação quanto para a animação. Este recurso à maneira de «trabalho gratuito » (SIMONET, 2018) não surpreende. O ensino superior sem dúvida alguma faz parte de mundos profissionais onde o trabalho gratuito vem com frequência completar ou substituir o emprego, especialmente para a margem de funcionários precarizados. Por um lado, o trabalho gratuito, porque permite, na universidade, assim como em outras esferas profissionais, a acumulação de capital simbólico (MENSITIERI, 2018), é alimentado por projeções de emprego futuro. Por outro lado, como a ambição de fazer bem seu trabalho é uma característica social marcante dos universos profissionais que prometem utilidade social (LINHART, 2009), a paixão pelo trabalho (LORIOL E LEROUX, 2015) também alimenta fortemente as formas de engajamento que tornam aceitável o trabalho gratuito. Aqui, é mais prontamente essa dimensão vocacional que se manifesta, e isso à custa de um superinvestimento que tende a reforçar nossa condição de precário, uma vez que é feito em detrimento de outras atividades mais « lucrativas » em termos de carreira, começando com a tese.

Entretanto, embora precária, não se trata tanto de «tornar a necessidade uma virtude » (BOURDIEU, 1979) como de «viver em repouso » (GRIGNON ET PASSERON, 1989) criando espaços de relativa autonomia ao lado de critérios dominantes para dar sentido ao nosso trabalho. Essa ambivalência é inerente à precariedade: se é uma forma particularmente poderosa de sujeição ao trabalho (CHAUVIN E JOUNIN, 2010), também pode permitir o uso tático dessa relação com a subordinação, que passa pela busca de espaços de autonomia e, portanto, de « afastamento » da dominação (SCOTT, 2008).

Pour autant, bien que précaires, il ne s'agit pas tant de « faire de nécessité vertu » (BOURDIEU, 1979) que d'«exister au repos» (GRIGNON ET PASSERON, 1989) en aménageant des espaces de relative autonomie à côté des critères dominants pour 
donner du sens à notre travail. Cette ambivalence est inhérente à la précarité : si elle est une forme particulièrement puissante de sujétion au travail (CHAUVIN ET JOUNIN, 2010), elle peut permettre aussi un usage tactique de ce rapport à la subordination qui passe par la recherche d'espaces d'autonomie et donc de «mise à distance » de la domination (SCOTT, 2008). A construção desse espaço autônomo, coletivo e singular foi, portanto, a oportunidade para seguirmos literalmente as injunções institucionais que contribuíram para a criação deste TD, ou seja, um acompanhamento rigoroso dos estudantes para promover sua entrada no mundo universitário. Para fazer isso e, a fim de dar - apesar de tudo - sentido ao nosso trabalho, construímos um dispositivo pedagógico centrado na auto-socioanálise, com uma perspectiva emancipadora do acesso aos saberes.

Essa escolha pedagógica pode encontrar explicações nos elementos convergentes de nossas trajetórias, que nos permitem construir um relacionamento positivo com a instituição universitária: origens sociais de classe média, capital escolar familiar relativamente marcado, com exceção de uma de nós, passagem pela universidade e não pelas grandes escolas, origens não parisienses, suburbana ou rural, proximidade geracional, o que pode favorecer o sentimento de identificação e empatia com nossos alunos ${ }^{9}$. Também temos em comum a crença no alcance emancipatório da escola como uma grande instância socializadora e na sua capacidade de desempenhar um papel fundamental nos destinos sociais. Essa convicção resulta de heranças sociais ou de elementos de trajetória. De fato, três de nós crescemos em famílias de professores nas quais foi transmitido um forte apego a valores e missões no serviço público. A última teve uma trajetória escolar na qual os professores tiveram um papel decisivo e estruturador. Isso provavelmente forjou disposições para assumir por sua vez o papel de professora e prestar atenção à dimensão pedagógica da profissão. Essas disposições também são algumas vezes redobradas por atividades ancoradas na educação popular ou no ativismo sindical ou associativo. Uma de nós, por exemplo, está envolvida nas atividades de uma

\footnotetext{
${ }^{9}$ Nossas características sociais: $1 / 41$ anos, mãe e pai professores, doutorado em sociologia validado após a retomada dos estudos, infância em um subúrbio pavillonnaire de interior; 2/34 anos, de pais universitários, cresceram em subúrbio de Paris e depois em Paris, bac S, iniciação do IUT e reorientação para a sociologia em uma universidade em um subúrbio de Paris; $3 / 29$ anos, pai professor de formação continuada, mãe conselheira para inserção profissional, infância em uma área rural no Oeste da França, bac $L$ depois curso de sociologia na universidade onde lecionamos até o doutorado; 4/27 anos, pai vendedor em loja, mãe dona da casa em proteção à criança, infância em áreas urbanas e peri-urbanas da cidade onde nossa universidade está localizada, escolaridade na mesma cidade: bac ES, hypokhâgne (classe preparatória), depois reorientação no primeiro ano de sociologia, até o doutorado.
} 
universidade popular, enquanto outro está há muito tempo envolvido em um projeto associativo no meio de um bairro popular da região parisiense.

Se nossos perfis e nossas experiências particulares puderam convergir para a construção desse dispositivo, isso se deve, em grande parte, à intensa emulação coletiva que se desenrolou naquele ano. Isso é explicado pela presença significativa, na sociologia da UFR, de estudantes de doutorado (três ATER, três monitores, vários trabalhadores ocasionais) e uma forte sociabilidade amigável entre muitos de nós. O ambiente de trabalho também contribui para isso: a acolhedora e animada sala dos doutorandos passa a ter, desde o primeiro semestre, características de uma «sala dos professores ", onde regularmente discutimos nossas experiências em sala de aula e nossas práticas pedagógicas (BOURGIN, 2011). Além disso, esses mesmos professores não-titulares ministram cursos para quase todos os alunos do primeiro ano, o que nos dá um conhecimento bem amplo de nossos grupos de estudantes. Essa sociabilidade permite, assim, formas de coordenação mais avançadas do que é comum observar nos primeiros ciclos universitários (GADEA ET SOULIE, 2000 ; SIRACUSA, 2008).

Embora cada um de nós tenha relatórios diferenciados sobre a tomada de iniciativas pedagógicas, nós rapidamente nos organizamos em um grupo de trabalho que funcionou como força motriz em nosso desejo de dar aulas de outra maneira. Na ausência de uma estrutura institucional que favoreça a reflexão pedagógica (sem reuniões de equipe, sala de professores, balanços de final de ano, harmonização de conteúdos caso a caso), criamos nossos próprios espaços de discussão. A título de ilustração, trocamos centenas de e-mails ao longo dos três anos, cujo assunto principal era sobre este curso, e discutimos com muita frequência o progresso de nossas respectivas sessões. Além desses tempos de trocas informais, nossa reflexão comum também assumiu formas mais formais. No início e no final de cada ano universitário, agendamos reuniões durante as quais repensávamos o dispositivo. Ao longo do ano, também compartilhamos, antes de cada sessão, nossos documentos do curso e compartilhamos e alimentamos nossas reflexões em um espaço de trabalho on-line. Ao fazer isso, conseguimos remover o espectro de um «isolamento pedagógico » (LE SAOUT ET LOIRAND, 1998) implantando coletivamente um dispositivo pedagógico original. 


\section{Um dispositivo a serviço de uma requalificação institucional e política dos alunos}

Ao estabelecer este curso, somos guiados por um certo número de opiniões pedagógicas que manifestam o desejo de «dar aula de outra maneira ». Por um lado, existe a intenção de se afastar da forma escolar para facilitar o acesso dos alunos à sociologia por meio de suas experiências; e, por outro lado, uma intenção extraescolar pela qual se aspira dar à auto-socioanálise uma dimensão coletiva e emancipatória. Precisamente por fazer parte de uma estrutura institucional, nosso dispositivo, no entanto, não escapa completamente da ambivalência da forma escolar.

\section{Quadro: 0 dispositivo de auto-socioanálise}

O objetivo do dispositivo pedagógico em questão é de conduzir os alunos a produzir uma auto-socioanálise. Trata-se assim de associar os elementos que os alunos possam perceber diretamente (quem são, de onde vêm, o que viveram, o que pensam) com a maneira pela qual a sociologia os analisa. (ou seja, sob o prisma de posições sociais, mecanismos de socialização, representações, relações sociais). A finalidade do exercício como nós o entendemos não é de neutralizar o sentido vivido, mas de lhe dar uma ressonância sociológica.

O trabalho em sala de aula gira em torno de apresentações orais sobre textos considerados trampolins para momentos de discussão coletiva, com foco na análise de trajetórias sociais. Estes momentos de debate ocorrem sistematicamente após os tempos das apresentações mais clássicas, ocupam um lugar central no dispositivo. Eles permitem o início do trabalho de auto-socioanálise com os alunos. As modalidades de trabalho em sala de aula visam, assim, fazê-los caminhar para a redação de seus arquivos. O curso se estabelece, sobretudo, a partir de uma coleção de textos que ilustram de várias maneiras a abordagem auto-socioanalítica (Beaud e Amrani, Ernaux, Umbigo, Sayad, Lahire, Wiseman, entre outros). É sequenciado em torno de quatro temas: as origens sociais e familiares, a relação com a escola e a trajetória escolar, as práticas culturais.

Para dar aos alunos as chaves para analisar esses textos, distribuímos « fichas conceituais » a partir das quais eles devem preparar suas apresentações. Para identificar a análise das trajetórias relatadas por esses textos, também os convidamos a usar exemplos de 
trajetórias convergentes ou divergentes extraídas de suas leituras, de filmes, de experiências pessoais.

Finalmente, propomos-lhes regularmente, a título de ilustração, rascunhos de autosocioanálise de nossas próprias trajetórias.

Além disso, para a realização de seu dossiê, nós pedimos aos alunos que articulem elementos de objetivação com dados mais simbólicos da ordem dos sentimentos (representações, afetos). Para isso, nós os guiamos na compilação dos dados factuais sobre as suas trajetórias, pela elaboração de uma árvore genealógica ou de uma faixa escolar. Para reintegrar a dimensão vivida, nós os convidamos a representar sua narrativa com anedotas. Finalmente, os estudantes podem contar com uma grade de perguntas que se torna um guia de entrevistas que os acompanha na escritura do dossiê.

\subsection{Construir coletivamente o saber}

Se nós Ihes propusermos de fazer uma auto-socioanálise em sala de aula, de forma coletiva, é que somos guiados principalmente por intenções que vão além do ambiente da instituição universitária, e que podemos qualificar como políticas. A partir de uma reflexividade que se conduz entre eles e conosco, procuramos construir a possibilidade de uma emancipação coletiva. Em outros contextos, especialmente profissionais (TRALONGO, 2015), a reflexividade pode com efeito ser encorajada no contexto de uma ação estratégica que convida os indivíduos a tornarem empreendedores de si mesmos (STEVENS, 2008), em que se conhecer melhor seria a primeira etapa para se reformar melhor. Bem ao contrário, nossa abordagem se baseia em uma concepção coletiva da jornada para a aquisição do conhecimento: trata-se tanto de atualizar os mecanismos sociais que ultrapassam a estrita estrutura individual, mas também de operar uma revelação de si mesmo coletivo, onde « ninguém se libera só, os homens se liberam juntos » (FREIRE, 1982). Nesta ótica, pensamos no exercício de auto-socioanálise como a ocasião de iniciar em sala de aula o processo de reflexividade entre os estudantes em suas trajetórias sociais.

Nesse sentido, a apropriação do exercício por um ou alguns alunos provoca com frequência, através do efeito «bola de neve ", uma dinâmica de entusiasmo comum pelo 
exercício, fazendo eco às suas experiências vividas. Isso ajuda a despertar neles afetos que podem funcionar como um motor para o desejo de entender, como testemunha este extrato de anotações feitas após uma aula:

A sessão é dedicada a um texto de Annie Ernaux. Fabien, Stephan e Maria devem «discutir» o texto. Depois que os dois primeiros vincularam o texto a um certo número de conceitos sociológicos, Maria explica, irritada, que ela escolheu se concentrar na parte da experiência narrativa da apresentação, porque se sente incapaz de entrar em uma reflexão conceitual porque ela ainda não domina perfeitamente a língua francesa. Ela então se envolve nas pontes entre o texto de Ernaux e sua própria jornada. Nascida no Senegal, ela viveu parte de sua escolaridade na Espanha, onde era muito boa aluna. Seus pais, acreditando que ela teria mais chances de "sucesso" na França, decidiram confiá-la ao tio e à tia aos 14 anos. Ela explica que, devido ao seu difícil aprendizado da língua francesa, passou de "muito boa aluna" aos olhos de seus professores espanhóis a "aluna com dificuldade" aos olhos dos educadores franceses. Ela fala sobre a vergonha e o sentimento de inferioridade violento que sentiu ao prosseguir sua educação na França, evocando os vereditos escolares negativos sobre ela. Ela relaciona esses dados simbólicos a elementos de trajetória, como suas deficiências em francês, sua trajetória migratória e o deslocamento sócio geográfico corolário, mas também as expectativas colocadas sobre ela por sua família. Seu testemunho abre a discussão. Os outros alunos, bem atentos desde que ela tomou a palavra a respeito de sua trajetória, reagem fazendo perguntas, depois intervêm para evocar suas próprias dúvidas quanto ao futuro e às diversas formas de pressão associadas. Começa então uma reflexão sobre a relação com a escola e seus determinantes, que se constrói coletivamente.

(Extraído de anotações de observação. Maria, 2017. Bac ES, profissão dos pais desconhecida, dossiê não entregue, interrupção do curso)

O investimento dos alunos no exercício e sua apropriação do mesmo como uma oportunidade de conscientização requer o estabelecimento de um clima favorável à emulação coletiva. Isso implica, principalmente, em «se unir » com os alunos e não aparecer (apenas) como representantes de uma autoridade institucional, para que eles percebam esse curso como o momento de « conivência entre o professor e os alunos, que se parece [...] um pouco com a que é compartilhada por aqueles que foram dados como vencidos, mas que sabem que ainda estão em pé » (TRUONG, 2010, pp. 77).

Para isso, usamos nossas semelhanças com os alunos de diferentes maneiras, mais ou menos conscientes. No início, essa proximidade é incorporada em um vocabulário, referências culturais e um estilo de vestuário relativamente comum devido à nossa 
proximidade geracional. Ela também foi reforçada durante movimentos sociais em que o comprometimento de alguns de nós diminuiu, pelo menos parcialmente, a distância simbólica dos alunos acompanhados em situações de mobilização. Também representamos essa proximidade quando, para mostrar a eles como iniciar a análise de suas trajetórias, Ihes oferecemos um rascunho de nossas próprias auto-socioanálises. Por fim, o exercício foi muitas vezes prolongado por discussões informais com estudantes que queriam abordar sua trajetória de maneira mais " protegida » nos corredores ou através de trocas de e-mails.

Esse entusiasmo coletivo não é necessariamente mecânico. Depende de condições ligadas ao conteúdo do curso, à atmosfera dentro do grupo, à existência ou não de estudantes «motores", ao horário da aula, à regularidade do TD e eventuais perturbações por elementos externos (como um movimento social), à carga de trabalho da professora ao lado, à sua nota de presença na classe etc. No final, vemos que as condições para o sucesso do exercício são baseadas em uma forma de « dádiva - contra dádiva » pedagógica que combina o investimento do professor e a adesão individual e coletiva dos alunos.

\subsection{Um dispositivo alcançado pela forma escolar}

Nosso curso é baseado na ambição de pensar diferentemente sobre a relação educacional com os alunos e com os saberes, mas enfrenta vários limites.

Primeiro, se nosso objetivo educacional é de oferecer um trabalho inclusivo aberto ao maior número de alunos, o próprio formato do exercício e os desafios que nele colocamos delineiam, implicitamente, uma espécie de « público ideal ». Nossas inclinações emancipatórias implicam que consideramos este curso como um espaço de reabilitação para certos tipos de estudantes, que podem ter dificuldade de encontrar seu lugar, seja dentro da instituição universitária ou mais amplamente no mundo social.

Assim, estamos nos dirigindo de forma latente a estudantes cujas trajetórias ou posições sociais podem parecer problemáticas, fragmentadas, dominadas. Esse exercício e a maneira como o trazemos pouco revelam o sentimento de linearidade e as trajetórias de relativa reprodução social. Além de ser o produto de nossos compromissos e nosso 
desejo « de utilidade social ", a constituição de nosso corpus de textos aumenta o foco implícito sobre um certo tipo de trajetórias «sinuosas » ou jornadas de deslocamento social que relata situações de violência simbólica.

Além disso, se pensarmos neste exercício como um meio de atenuar os obstáculos que possam limitar a entrada de certos alunos na sociologia, nosso curso não é, no entanto, autossuficiente: seu sucesso depende em grande parte do que os alunos aprendem em disciplinas preparatórias. Este dispositivo pedagógico só funciona, de fato, se os estudantes estiverem minimamente equipados do ponto de vista teórico para analisar o material empírico acumulado em sua própria trajetória. Do mesmo modo, se nosso dispositivo quiser ser mais democrático, ele repousa apesar de tudo na capacidade, social e academicamente situada, de ler, recriar textos e dominar conceitos sociológicos. Por isso, apenas derruba em parte os obstáculos para o acesso ao conhecimento. Encontramos ali as clivagens que distinguem os alunos «escolares » dos alunos cujos recursos sociais lhes permitem tomar iniciativas e identificar o esperado criptografado por trás das instruções dos professores (BOURDIEU ET PASSERON, 1964). Como resultado, essa aparente ruptura com a forma universitária implica uma forma « de hiper escolarização implícita » (BONNÉRY, 2007), nossa abordagem reencenando parcialmente os vieses sociocognitivos das pedagogias do desvio (BONNERY ET RENARD, 2013).

Finalmente, além da violência intrínseca da revelação sociológica de si (AMRANI e BEAUD, 2005), a estrutura universitária pode reforçar a violência simbólica do exercício. De fato, exige que as produções dos alunos sejam rastreadas por critérios de classificação acadêmica. Esse ponto suscitou muitas discussões entre nós, tanto na objetivação das anotações quanto no próprio fato de avaliar um exercício no qual os alunos revelam elementos íntimos. Diante do medo manifestado por certos alunos com a ideia de que poderíamos « anotar » suas vidas, e diante do desconforto com a ideia de correr o risco de redobrar a violência dos vereditos da universidade, fizemos certas arbitragens em nossos métodos de pontuação. Assim, retribuímos o envolvimento dos alunos no exercício, atribuindo a média a todos aqueles que se esforçavam a mínima na redação do dossiê. Também valorizamos as cópias incorporadas e habitadas sendo muito flexíveis em questões de forma que, em outros cursos, teriam sido sancionadas (erros de ortografia, registro familiar, sintaxe defeituosa). No entanto, esse ponto coloca um limite 
institucional para a «nobreza» dos objetivos que estabelecemos para nós mesmos. A nota, inerente à orientação da universidade, atua como um chamado à ordem. Embora nossas intenções sejam em parte extras institucionais e visem transformar o relacionamento entre nossos alunos e o mundo, o reconhecimento que atribuímos ao trabalho deles, em última instância, permanece vinculado à estrutura universitária e, portanto, dependente das sanções, positivas ou negativas, transmitidas pelas notas.

\section{3. (Re)qualificar o sucesso dentro e fora da instituição}

As diferentes apropriações que este projeto pedagógico viabiliza entre os alunos, bem como o significado que a experiência pedagógica tem para nós, remetem a variadas formas de sucesso. Em termos da experiência do aluno, alguns, avaliados pela nota e pelo grau de adequação à instrução, atendem às expectativas clássicas da instituição universitária, enquanto outros, que o critério da nota não representa o objetivo final, são os casos em que a ambição da reflexividade se materializa na requalificação que os estudantes operam em sua trajetória social. Em termos da experiência de ensino e em um contexto em que as carreiras são avaliadas por critérios acadêmicos, essa abordagem pedagógica é uma oportunidade para criarmos critérios alternativos para definir o profissionalismo e a « sensação de um trabalho bem feito » (HUGHES, 1963).

\subsection{Modos de apropriação diferenciados do exercício}

O envolvimento diferenciado dos alunos no exercício pode ser analisado de acordo com dois critérios: o do sucesso acadêmico do exercício sancionado por uma nota que contribui para uma requalificação objetiva; e o de investimento em um exercício de auto coerência, que contribui para uma requalificação para si mesmo. Na ausência de uma análise sistematizada ${ }^{10}$, podemos categorizar pelo menos quatro tipos de recepção de exercícios.

\footnotetext{
10 Tal abordagem exigiria uma análise mais fina da recepção que os estudantes fazem desse dispositivo, fazendo a correspondência entre suas características sociais com as diferentes modalidades de realização do exercício, mas também objetivando sua originalidade, comparando as notas deste TD com as de outros cursos.
} 
Um primeiro tipo corresponde a esse "público-alvo" ao qual nosso dispositivo se refere implicitamente. De fato, parece que aqueles que enfrentaram formas de deslocamento mais ou menos agudas (sociais, migratórias, geográficas) têm uma tendência mais forte a aderir ao exercício. Além da propensão a falar sobre si mesmo de pessoas que experimentaram uma mobilidade social (POLIAK, 2002), a sociologia lhes fornece uma grade de inteligibilidade das situações que elas podem ter vivido no modo de mudança social (MAUGER E FOSSÉ, 1977; SAYAD, 2006). A esse respeito, o dossiê de John, escrito em um único rascunho, no qual palavras crioulas se misturam com palavras francesas com ortografia bem aleatória, é esclarecedor. John nasceu em La Réunion e seu primeiro ano em sociologia também corresponde à sua chegada, sozinho, à metrópole. Ele conta como, durante seus "anos de colégio", dois modelos de identificação se apresentaram a ele, o de seu meio-irmão já envolvido em uma "carreira" de pequeno delinquente e o de seu primo, personificando a imagem do bom aluno.

A chegada ao quarto ano foi o momento mais significativo da minha vida escolar, porque peguei na mão e tinha decidido ir para o ensino médio (lycée) geral porque minha mãe, durante suas críticas, costumava me comparar ao meu primo que, ele, tinha excelentes notas na escola ... ele estava em um conservatório de música e quando íamos à sua casa, havia sempre uma biblioteca de livros, muitos jogos educativos e muitos computadores. O que me surpreendia, porque em casa o único livro que se podia ver era uma Bíblia e algumas estórias em quadrinhos que eu trazia da escola. (...) Ele tinha uma cultura escolar que a escola valoriza, dessas práticas educacionais, mas também por sua maneira de se comportar... enquanto eu era exatamente o contrário e devido à diferença do meio social e capital cultural, porque seu pai era contador profissional e sua mãe assistente de direção.

(Extraído do dossiê de John. Bac STMG, pai funcionário agente supervisor e a mãe do lar. 16 no exercício; 10,22 de média geral anual)

De maneira geral, os pontos de relevância biográfica servem como ponto de apoio à escrita e permitem entrar com mais facilidade na lógica do exercício. Aqui, a trajetória biográfica desses estudantes torna-se um recurso que pode, quando o exercício termina com uma boa nota, trabalhar em uma requalificação escolar que os assegure, ou seja, que os reabilite parcialmente na área da universidade. No entanto, isso está longe de ser o caso de todos aqueles que experimentam essa situação de deslocamento social. 
O segundo perfil de dossiê refere-se a estudantes que possuem «capital

militante ». Já acostumados a falar sobre si mesmos e a desconstruir o mundo social como parte de sua prática militante, esses alunos também se envolvem totalmente no trabalho da auto-socioanálise. De maneira geral, eles também são com frequência os que mais participam nos debates organizados em sala de aula e animam as discussões em torno da máquina de café, trazendo o exercício para fora da arena estabelecida da classe. O exemplo de Tamara ilustra bem a propensão à reflexividade desse tipo de perfil:

Eu só conseguia pensar que estaria no meu elemento [com este exercício], como uma continuidade no meu aprendizado e no meu ativismo. (...) Quando ele falou da necessidade de comer orgânico, eu sabia que esse não era o meu caso, mas eu procurava embelezar a realidade, quando ele dizia que não tinha televisão, eu evitava dizer que a televisão é fundamental para nós, quando ele fala sobre sua Bretanha, independente e oprimida pela República Francesa, sou discreta, mencionando de passagem minhas origens mauritanas, quando ele evocava sua música clássica ou metálica, eu não evocava a música popular que eu escuto, quando ele falava de capitalismo, eu fingia saber tudo sobre o assunto. Mas, neste caso, eu estava vivendo uma situação de violência simbólica, na qual tentava fazer muitos esforços, para preencher minhas lacunas e estar à altura.

(Extraído do dossiê de Tamara, 2017. Bac S, pai funcionário da categoria C e a mãe do lar. 17,5 no exercício; 13,91 de média geral anual)

Vê-se bem aqui no trabalho a maneira pela qual a aluna enfatiza minuciosamente as formas de dissonância que ela sente em relação à distância social vivida no contato com o amigo. Para explicar o deslocamento, esses estudantes frequentemente mobilizam uma oposição com outra pessoa que serve de suporte para a narração de si mesmos.

Além desses dois tipos de perfis, que são particularmente revelados no contexto desse exercício singular e dos recursos extraescolares que ele mobiliza, existe um terceiro perfil, que corresponde a estudantes com fortes recursos acadêmicos. Estes últimos conseguem entender os micros deslocamentos, em termos sociais, geracionais ou culturais. Nesses casos, é, portanto, o domínio dos recursos escolares e o bom entendimento das leituras sociológicas (que se fazem em grande parte fora do curso) que possibilitam enfatizar eventos biográficos a priori inofensivos. Como este extrato de dossiê: 
Parece-me assim mesmo que no tempo do colégio eu estive entre dois meios sociais. Embora eu tenha sido confrontado com uma certa diversidade social, o perfil dominante do colégio particular do centro da cidade era a classe média alta, quero dizer rica. Minhas redes de amigos se voltaram principalmente para essas pessoas, eu queria e tive a impressão de ter "entrado no molde ", o que passava principalmente pelas normas de vestuário, de linguagem, de comportamento, que contrastavam com as de meus amigos de infância, a maioria dos quais foi trabalhar desde o colégio, e minha mãe sempre me perguntava "você não os vê mais ? ». Uma situação como essa, também senti algumas vezes com meus pais, com mal-entendidos quando se tratava de ter esta ou aquela coisa para estar de acordo com meus camaradas, e que meus pais apontavam a inutilidade ou a simples função de parecer.

(Lucas, bac ES, 2017, pai VRP, mãe agente de entretenimento, 18 no exercício, 14,80 de média anual)

Este aluno explica como ele modela suas atitudes de acordo com os grupos de colegas com quem conviveu e os códigos em vigor nesses últimos, relacionando sempre a análise de suas interações com dados de objetificação (local de escolarização, de moradia, de socialização, características sociais dos amigos). Ele também destaca como essas socializações secundárias participaram de sua aquisição de novos códigos, de novos valores ou aspirações (escolares, profissionais, esportivos) e as discrepâncias que isso poderia gerar com seus pais ou amigos desde a infância. Assim, devido ao seu bom entendimento da sociologia e sua capacidade de identificar as diferentes cenas em que ele evolui, ele consegue apontar minuciosamente os efeitos vividos de uma leve mobilidade social.

Ao contrário, os alunos que não possuem recursos escolares específicos e cuja trajetória social pode ser lida sob uma aparente linearidade, se encontram duplamente desafiados pelo exercício, tanto na substância quanto na forma. Do ponto de vista sociológico, esses estudantes poderiam pertencer ao grupo social com contornos vagos dos «pequenos recursos » (CARTIER et al., 2008) : disposições sociais que os devolvem à classe média, trajetória escolar média, pouca ou nenhuma mobilidade geográfica intergeracional. O exercício de auto-socioanálise que lhes é solicitado parece, assim, enviar alguns desses estudantes de volta à «banalidade» de sua existência. Esse sentimento é reforçado pela exemplaridade das trajetórias de desertores propostos para leitura na coleção, conforme sublinhado por esta aluna em um e-mail enviado à sua professora: 
Sinto que não tenho muito o que contar porque sempre tive um relacionamento bem "normal" na escola, nunca encontrei dificuldade alguma, por isso tenho a impressão de não ter coisas interessantes a dizer. [...] Meus pais estão sempre juntos e se dão muito bem, meu irmão também, nunca me mudei, minha família inteira mora perto de mim... Dado que discutimos principalmente textos escritos por pessoas de origens bastante populares, sinto que não sou legítimo para este tipo de exercício...

(Extraído de um e-mail de Chloé, 2016. Pai quadro hospitalar, mãe responsável de recursos humanos, Bac ES, 15 no exercício, 13,5 de média anual)

A expressão de uma forma de ilegitimidade para se dizer é muitas vezes redobrada pela dificuldade de entender os riscos de moldar o exercício. A ausência de uma estrutura rígida quanto ao relato escrito pode suscitar mal-entendidos entre os alunos, que confinam seu trabalho ao registro descritivo ou a uma grade de leitura psicologizante de sua jornada (diário, caderno de queixas, autopromoção de si mesmo etc.). Nesses casos, os estudantes não veem o interesse de si mesmos em dizerem a si mesmos, nem mesmo o interesse puramente acadêmico de mobilizar uma análise dos mecanismos sociais.

Além dos recursos clássicos da escola, os alunos que tiram o máximo proveito deste exercício são afinal aqueles que estão prontos para compreender a "auto exterioridade social »(CINGOLANI, 2003).

\subsection{Auto apropriação da auto-socioanálise}

Como parte deste projeto, nos encontramos em uma posição que difere de nossos cursos usuais. As anotações que colocamos para os alunos não são um indicador suficiente para restaurar o entusiasmo que envolve a experiência. Este exercício, pela maneira como o realizamos e por seu formato reflexivo, gera de fato uma forte implicação entre os alunos, que vai além dos desafios do reconhecimento direto de seu trabalho pela instituição universitária, como testemunha o paradoxo sublinhado por este aluno:

Marquei um encontro com os alunos na sala dos professores para coletar seus arquivos de auto-socioanálise. Loïc, entregando seu trabalho para mim, comenta, provocadoramente, «por que existe um coeficiente tão pequeno? Pensei sobre isso e disse a mim mesmo que era um limite mais estratégico não o devolver e poder trabalhar duro em materiais com 
grande coeficiente... ». Tomando nota desse cálculo, pergunto a ele sobre o investimento que ele finalmente fez no exercício. Pelo olhar resoluto de quem foi pego no jogo, ele continua: «Bem, ao mesmo tempo em que estive totalmente envolvido durante todo o semestre... eu tinha um documento onde escrevia todos os pontos que queria abordar e eu não consegui afinal nem colocar tudo nas 15 páginas. » (Nota de observação de 29 de abril de 2019)

Assim formulada, a observação deste aluno cristaliza a tensão que torna este curso singular aos nossos olhos e aos olhos dos alunos. O investimento, temporal e emocional, que é solicitado aos estudantes na auto-socioanálise não é de forma alguma proporcional à rentabilidade universitária do exercício ${ }^{11}$. O exercício é, portanto, baseado em um compromisso percebido como mais forte, uma vez que não se reflete na média geral, mas na carreira universitária formal dos estudantes. Numerosos índices atestam essa apropriação do exercício pelos alunos, como estudantes que abandonam o curso e desertam os parciais, mas que ainda entregam o dossiê, ou e-mails de alunos que nos agradecem pelo exercício ou meses depois, novamente entram em contato, em busca de conselhos, para nos dizer que eles continuam suas auto-socioanálises. Este aluno, por exemplo, sublinha, por contraste, a atração que o exercício exercia sobre ele, no início de sua interrupção do curso:

De início, suas intenções não poderiam ter sido mais justas, em colocar o aluno no centro de uma análise sociológica, para construir uma reflexão real sobre sua identidade social com essa auto-socioanálise. (...) Peço desculpas por não ter devolvido nada, mesmo que seja apenas para mim. No entanto, eu queria que esse caso estivesse quase terminado, mas fiquei paralisado, bloqueado por um contexto inoportuno. Uma enésima produção inacabada. (E-mail de Matéo, de 18 de maio de 2019)

Além disso, a criação em 2018-2019 por ex-alunos de oficinas de auto-socioanálise autogerenciadas e abertas a todos é uma das manifestações mais concretas desse compromisso no processo, à margem do reconhecimento acadêmico.

\footnotetext{
${ }^{11}$ Todos os coeficientes juntos valem, portanto, o coeficiente 1 de 60 para o cálculo da média anual de estudantes.
} 


\subsection{Uma requalificação profissional ambivalente no campo acadêmico}

Este exercício não opera apenas formas de requalificação para os alunos, mas também para nós mesmos. Nosso estatuto precário, porque implica em « realizar com as oportunidades » (CERTEAU, 1990), coloca-nos em um registro tático em relação à instituição universitária e suas injunções, tanto pedagógicas quanto acadêmicas. A esse respeito, essa experiência é a ocasião para uma reciclagem profissional ambivalente: por um lado, foi possível atuar em parte na definição e no significado que damos ao nosso trabalho; por outro, a constituição dessa experiência como objeto de pesquisa a requalifica em um registro mais legítimo em termos de construção de carreira.

Assim, operamos uma forma de requalificação do valor atribuído à educação, a fim de lhe proporcionar uma dimensão ética e política. Neste exercício, como mencionamos acima, a aposta educacional difere em parte daquela que é implementada em outros cursos. Aqui, a promessa de recompensa pelo investimento de nossos alunos reside certamente na classificação (pelo menos uma classificação branda que não seja inferior a 10, no máximo uma classificação que não hesite em subir até 20). Mas a promessa também se baseia nas contribuições pessoais que os alunos devem encontrar lá e cujos efeitos serão medidos em seu relacionamento com o mundo.

Este pacto educacional pressupõe que coletemos as histórias entregues pelos alunos. Essa relação de confiança apresentada como extrapolando a estrita estrutura acadêmica às vezes está ancorada em uma relação empática, quase afetiva, com os alunos. Tal postura é semelhante à «preocupação com o outro », característica do trabalho de «cuidar» (MOLINIER, 2013), que supõe que a ética profissional esteja articulada à ética moral. Essa postura se reflete sobretudo no tom que às vezes mobilizamos nas correções de arquivos ${ }^{12}$, à imagem deste trecho:

Compilar minha vida assim me deprimiu um pouco, porque muitas coisas empreendidas terminaram em fracasso. Minha relutância em produzir este exercício certamente vem daí. Mas acho que é inevitavelmente interessante ganhar altura e dar uma nova direção às nossas trajetórias. (Extrato do arquivo de Alexandre, 2017, retomada dos estudos, mãe da

\footnotetext{
${ }^{12} \mathrm{~A}$ dimensão afetiva também está mais presente na parte feminina de nosso coletivo, que, desse ponto de vista, não se opõe às características clássicas do trabalho assistencial.
} 
escola primária e pai sênior de uma administração pública, DAEU, 16 no exercício, média anual de 10,92)

O comentário do professor na margem, em reação direta com esse ponto de sua cópia:

Não estou aqui para julgar ou opinar sobre sua vida, e meu comentário provavelmente é visto e revisto, mas isto que você está contando não se refere tanto ao fracasso, mas a um caminho no qual cada etapa teve um papel importante, provocou uma « tomada de consciência (...) Uma vida nunca (...) é desenhada antecipadamente (mesmo se a sociologia determinística Bourdieusiana às vezes possa dar essa impressão de « inércia » do social), e você também pode ver cada episódio como um elo de uma corrente que o levou a suas aspirações atuais.

Aqui, o professor deixa o estrito papel de corretor aplicando uma grade «objetiva» de critérios e se coloca no registro da escuta e do apoio moral. Como precisamente nossa abordagem envolve a adoção da postura de guias e não apenas de avaliadores, extraímos dela uma forma de requalificação simbólica de nosso papel como professor, entendido em termos de sua utilidade social. Esse sentimento de «missão cumprida» é sentido com mais força quando, pelo formato do curso, atraímos estudantes que até então eram pouco reconhecidos pela instituição de ensino.

No entanto, embora encontrássemos, de fato, formas de valorizar nosso trabalho alternativas aos critérios de excelência universitária, nossa abordagem permanece ambivalente e é realizada em uma estrutura que não é hermética às expectativas do campo acadêmico. Redigir um artigo em uma revista científica altamente reconhecida ou nos comunicar, perante colegas, em meio a colóquios sobre a pedagogia, também são formas de transformar essa experiência pedagógica em um recurso passível de ser mobilizado no campo profissional. Por fim, neste artigo, requalificamos cientificamente uma prática pedagógica de ensino, estabelecendo-a como objeto de pesquisa, ancorando-a assim na parte mais valorizada das atividades acadêmicas.

\section{Conclusão}

Neste artigo, mostramos que o « sucesso » de um dispositivo pedagógico depende de uma configuração singular, o que implica considerar o trabalho docente na 
universidade a partir de sua estrutura institucional, ao reencaixá-lo em elementos da trajetória e de formas extraprofissionais de engajamento que contribuem para moldar a relação com o trabalho daqueles que o exercem.

Este exercício de auto-socioanálise finalmente constitui para seus protagonistas uma forma de sucesso alternativo, que não é perceptível através das categorias da instituição e de seus indicadores numerados. Para os professores, este curso metodológico de seis sessões de duas horas para um público L1 pesa pouco em um currículo acadêmico. Para os alunos, a pontuação obtida neste TD é a que vale proporcionalmente menos no cálculo de sua média anual. O sucesso do exercício, como é vivido pelos professores e parte dos alunos, por outro lado, é compreendido em termos de elementos qualitativos, pelo investimento que cada um coloca nele e o que as duas partes obtêm dele em termos de requalificação de suas experiências.

Paradoxalmente, foi a desvalorização de uma área da educação universitária que possibilitou formas alternativas de valorização do nosso trabalho, à custa de um superinvestimento de nossa parte. Isso se coloca de certa maneira contra a corrente da dinâmica política institucional e constitui uma maneira de compensar «à margem » as reduções de recursos que afetam o ensino superior. Devido aos nossos perfis e ao consenso de trabalho que nos une, nos sentimos envolvidos na transmissão de saberes e motivados pela vontade de fazer com que todos os nossos alunos tenham sucesso. Isso nos leva, apesar de uma estrutura pouco favorável ao investimento pedagógico, a « fazer com » - o que torna parte do nosso trabalho invisível - mas, entretanto, a «fazer assim mesmo », participando de facto da manutenção da instituição. 


\section{Referências}

AMRANI Younes et BEAUD Stéphane, 2005, “ Pays de malheur ! ”, Paris, La Découverte.

ANNOOT Emmanuelle, 2012, La réussite à l'université, De Boeck Supérieur.

BODIN Romuald et MILLET Mathias, 2011, «L'université, un espace de régulation.

L'« abandon » dans les 1ers cycles à l'aune de la socialisation universitaire », Sociologie, vol. $2, \mathrm{n}^{\circ} 3$, p. $225-242$.

BODIN Romuald et ORANGE Sophie, 2013, L'Université n'est pas en crise : Les transformations de l'enseignement supérieur : enjeux et idées reçues, Bellecombe-enBauges (Savoie), Editions du Croquant.

BONNERY Stéphane, 2007, Comprendre l'échec scolaire : élèves en difficultés et dispositifs pédagogiques, Paris, La Dispute.

BONNERY Stéphane et RENARD Fanny, 2013, « Des pratiques culturelles contre l'échec et le décrochage scolaires. Sociologie d'un détour ", Lien social et Politiques, n 70, p. 135-150.

BOURDIEU Pierre, 1979, La Distinction : Critique sociale du jugement, Paris, Les Editions de Minuit.

BOURDIEU Pierre et PASSERON Jean-Claude, 1964, Les héritiers : Les étudiants et la culture, Paris, Les Editions de Minuit.

BOURGIN Joëlle, 2011, « Les pratiques d'enseignement dans l'université de masse : les premiers cycles universitaires se scolarisent-ils ? », Sociologie du Travail, vol. 53, $n^{\circ}$ 1, p. 93-108.

CARTIER Marie, COUTANT Isabelle, MASCLET Olivier et SIBLOT Yasmine, 2008, La France des « petits moyens »: Enquêtes sur la banlieue pavillonnaire, Paris, La Découverte.

CERTEAU Michel de, 1990, L'invention du quotidien, tome 1 : Arts de faire, Paris, Gallimard.

CHARPENTIER Isabelle et ERNAUX Annie, 2005, " "La littérature est une arme de combat" ", in Rencontres avec Pierre Bourdieu, G. Mauger éd., Bellecombes-en-Bauges France, Editions du Croquant.

CHAUVIN Sébastien et JOUNIN Nicolas, 2010, «L'externalisation des illégalités.

Ethnographie des usages du travail "temporaire" à Paris et Chicago », in Les paradoxes de l'économie informelle : à qui profitent les règles?, N. Barbe et F. Weber éd., Paris, Karthala.

CINGOLANI Patrick, 2003, La république, les sociologues et la question politique, Paris, La Dispute.

CINGOLANI Patrick, 2014, Révolutions précaires, Paris, La Découverte. 
DAVID Marie, 2017, Les savoirs comme construction collective. Enquête au lycée général et en première année à l'université, Thèse de doctorat, Nantes, Université de Nantes.

DEAUVIEAU Jérôme, 2007, « Observer et comprendre les pratiques enseignantes », Sociologie du Travail, $n^{\circ} 1$.

FREIRE Paulo, 1982, Pédagogie des opprimés, Paris, Maspero.

GADEA Charles et SOULIE Charles, 2000, « Réflexions sur une expérience d'initiation à la recherche en sociologie à l'Université (1994-2000) ", Genèses, vol. 39, n 1, p. 155-171.

GRIGNON Claude et PASSERON Jean-Claude, 1989, Le Savant et le populaire.

Misérabilisme et populisme en sociologie et en littérature, Paris, Gallimard.

HILGERS Mathieu, 2006, «La responsabilité sociologique : retour sur l'entreprise critique de Pierre Bourdieu », Recherches sociologiques et anthropologiques, vol. 37, $n^{\circ}$ 37-1, p. 43-63.

HUGHES Everett C., 1963, «Professions », Daedalus, vol. 92, n 4, p. 655-668.

JOUNIN Nicolas, 2014, Voyage de classes, Paris, La Découverte.

KAKPO Séverine et LEMETRE Claire, 2019, «L'auto-socioanalyse : un outil au service de la démocratisation universitaire ? Retour critique sur une expérience pédagogique », Sociologos. Revue de l'association française de sociologie, $n^{\circ} 14$.

LE SAOUT Rémy et LOIRAND Gildas, 1998, «Les chargés d'enseignement vacataires : les paradoxes d'un statut perverti », Genèses. Sciences sociales et histoire, vol. 30, $n^{\circ} 1, p$. 146-156.

LINHART Daniele, 2009, Travailler sans les autres ?, Paris, Le Seuil.

LORIOL Marc et LEROUX Nathalie, 2015, Le travail passionné : L'engagement artistique, sportif ou politique, Toulouse, Erès.

MAUGER Gérard et FOSSE Claude, 1977, La vie buissonnière, Paris, Maspero.

MENSITIERI Giulia, 2018, « Le plus beau métier du monde. » Dans les coulisses de l'industrie de la mode, Paris, La Découverte.

POLIAK Claude, 2002, « Manières profanes de « parler de soi » », Genèses, vol. no47, n², p. 4-20.

SAYAD Abdelmalek, 2006, L'immigration ou les paradoxes de l'altérité. 2. Les enfants illégitimes, Paris, Raisons d'agir.

SCOTT James C., 2008, La Domination et les arts de la résistance : Fragments du discours subalterne, Éd. Amsterdam.

SIMONET Maud, 2018, Travail gratuit : la nouvelle exploitation ?, Paris, Textuel. 
SINIGAGLIA Jérémy, 2018, « "Mes enfants l'heure est grave : il va falloir faire des économies » ». Actes de la recherche en sciences sociales, $n^{\circ}$ 221-222, p. 20-37.

SIRACUSA Jacques, 2008, Vacances Sociologiques. Enseigner la sociologie à l'université, Saint-Denis, Presses universitaires de Vincennes.

SOULIE Charles, 2002, "L'adaptation aux « nouveaux publics » de l'enseignement superieur : auto-analyse d'une pratique d'enseignement magistral en sociologie », Sociétés contemporaines, vol. $48, n^{\circ} 4$, p. 11.

Soulié CHARLES, 1996, «PRECARITE DANS L'ENSEIGNEMENT SUPERIEUR », ACTES DE LA RECHERCHE EN Sciences Sociales, vol. 115, $n^{\circ} 1, p$. 58-64.

STEVENS Hélène, 2008, «Quand le psychologique prend le pas sur le social pour comprendre et conduire des changements professionnels », Sociologies pratiques, vol. $17, n^{\circ} 2$, p. 1-11.

TRALONGO Stéphanie, 2015, « Devenir un professionnel de la professionnalisation des étudiants : un changement accompagné dans les cultures et pratiques des enseignants et enseignants-chercheurs? ", Éducation et socialisation. Les Cahiers du CERFEE, $n^{\circ} 38$.

TRUONG Fabien, 2010, «Enseigner Pierre Bourdieu dans le 9.3 : ce que parler veut dire », Idées économiques et sociales, vol. 160, $\mathrm{n}^{\circ} 2$, p. 72-77. 